\title{
Association of health involvement and attitudes towards eating fish on farmed and wild fish consumption in Belgium, Norway and Spain
}

\author{
Themistoklis Altintzoglou • Filiep Vanhonacker • \\ Wim Verbeke · Joop Luten
}

Received: 27 May 2009/ Accepted: 2 August 2010/Published online: 24 August 2010

(C) The Author(s) 2010. This article is published with open access at Springerlink.com

\begin{abstract}
Consumers in many European countries do not equally meet the recommended daily intake levels for fish consumption. Various factors that can influence fish consumption behaviour have been identified but limited research has been performed on fish consumption behaviour, discriminating between farmed and wild fish. The present survey study confirmed differences in total fish consumption, farmed fish and wild fish consumption behaviour in Belgium, Norway and Spain. Spanish consumers consumed more frequently fish of each category than Norwegian consumers. Belgian consumers reported the lowest consumption frequency of fish. Accordingly, health involvement and attitudes towards fish consumption decreased from Spain over Norway to Belgium, suggesting a positive association of health involvement and attitudes towards fish consumption with total fish consumption. Similar effects were found for farmed and wild fish consumption. In general consumers in all countries were poorly aware of the origin of the fish they consume, despite the mandatory indication of origin on fish labels. Across countries, an increased awareness about fish origin was found with increased fish consumption. The findings of the study indicate that farmed and wild fish consumption should be further stimulated among Belgian, Norwegian and Spanish consumers in association with a healthy and positive meal. Additionally, given the limited awareness of the origin of fish, transparency on the issue of farmed origin will be important in order to anticipate potential adverse communication.
\end{abstract}

Keywords Attitudes - Consumers - Fish consumption - Health involvement · Farmed fish · Wild fish

\footnotetext{
T. Altintzoglou $(\bowtie)$

Nofima Marine, Muninbakken 9-13, PoBox 6122, 9291 Troms $\emptyset$, Norway

e-mail: themis.altintzoglou@nofima.no

F. Vanhonacker · W. Verbeke

Department of Agricultural Economics, Ghent University, Coupure links 653,

9000 Ghent, Belgium

J. Luten

Nofima Market, Muninbakken 9-13, PoBox 6122, 9291 Troms $\emptyset$, Norway
} 


\section{Introduction}

Fish has been repeatedly described as a health promoting food category (Mozaffarian and Rimm 2006; Sidhu 2003). However, consumers in many European countries do not equally meet the recommended daily intake levels of consuming two servings of fish per week (Scientific Advisory Committee on Nutrition, Committee on toxicity of chemicals in food 2004; Welch et al. 2002).

Various factors that can influence consumers' fish eating behaviour have been identified. Among them are product quality (Verbeke et al. 2007b), attitudes towards choosing fish for a meal (Brunsø 2003), involvement in seafood (Olsen 2001), food choice habits (Honkanen et al. 2005), beliefs about benefits and risks related to health (Verbeke et al. 2005), convenience (Olsen et al. 2007; Rortveit and Olsen 2007), age (Olsen 2003) and health involvement (Olsen 2003; Pieniak et al. 2008).

It is generally acknowledged that the intrinsic sensory characteristics of a food product and the extrinsic characteristics such as health claims influence considerably eating and drinking behaviour (Köster 2009). Consumers report positive attitudes towards healthier products and strong intentions to consume them (Kozup et al. 2003). However, the possibility that those healthier products do not end up being the final choice is a reality (Köster et al. 1987; Weijzen et al. 2008). This is a result of the implicit tendency to report behavioural intentions based on past behaviour and not based on deliberate descriptions of plans (Bem 1972).

Some research has been performed on the image of seafood products, the image of seafood production methods and its impact on fish consumption behaviour. Consumers perceive farmed fish as being of lower quality as compared to fish captured in the wild (Kole 2003; Verbeke et al. 2007a, b). It was recently suggested that despite its possibly preferable sensory properties, the image of fish from aquaculture can influence the perception of fish products negatively (Kole et al. 2009; Luten et al. 2002). The image of farmed fish has been suggested to be less positive than the image of wild fish. Even though the overall image of farmed fish is still positive, the difference relative to wild fish might be a bottleneck for the development of economically viable and sustainable aquaculture and one of the reasons behind stabilising fish consumption.

One of the aims of the present study was to describe the reported total fish consumption, farmed fish consumption and wild fish consumption in Belgium, Norway and Spain. Additionally, the aim of this study was to assess consumers' involvement in health issues and consumers' attitudes towards fish consumption. Moreover, the relationship of health involvement and attitudes towards eating fish with fish consumption behaviour in the three countries will be analysed. Furthermore, this study aims at describing the latter effects on the consumption of farmed and wild fish. Finally, consumers' awareness of the origin of the fish they consume will be discussed.

\section{Materials and methods}

\section{Research approach and sampling}

Quantitative descriptive data were collected through a cross-sectional consumer survey in Belgium, Norway and Spain. The selection of the countries was informed by their partial representation of Northern, Mid and Southern Europe and the considerable differences in the fish consumption levels and habits between those countries (Welch et al. 2002). The 
population was defined as the main responsible for food purchasing in the household in the age range between 20 and 60 years. Total sample size was 1,319 respondents, i.e. around over 400 participants in each of the three considered European countries. The fieldwork for the study was performed by a professional market research agency (IPSOS).

Participants were randomly selected from the representative IPSOS European online access consumer panel (Malhotra and Peterson 2006). Such an online access panel, which was used as the sampling frame for this study, is a large-scale and representative panel of individuals (used as sampling unit), who have been recruited through off-line recruitment procedures. The use of an off-line recruitment procedure is meant to reduce possible selection bias in web-based surveys. Thus, the panel consists of more than 600,000 individuals in Europe who were previously approached by the research agency for instance in shopping malls or in the street and asked about their willingness to participate on a regular basis in market researches. Participants for this specific study were selected from the panel using stratified random sampling and proportionate stratification in line with the national population distributions for age (in the range 20-60 years) and region. All contact and questionnaire administration procedures were electronic and web-based. The fieldwork was performed in the beginning of December 2007.

Detailed socio-demographic characteristics of the national and pooled samples are provided in Table 1. Gender distribution reflects the selection of the main responsible for food purchasing with a majority of females. Different age groups from the range 20-60 years were nearly equally represented. The sample further varies in terms of household size, education level, presence of children and regional distribution (Table 1).

\section{Questionnaire content, measurement and scaling}

A master questionnaire was developed in English and translated in the national languages using the procedure of back-translation to ensure linguistic equivalence (Brislin 1970; Maneesriwongul and Dixon 2004). Following back-translation, the questionnaire was extensively pre-tested by the researchers in order to identify and eliminate potential problems. Fieldwork started after editing, correcting, electronic programming and additional pre-testing of the electronic version of the questionnaire.

Participants were asked to complete the structured electronic questionnaire on their own. Four survey questions were relevant within the scope of the present study. First, consumers' self-reported consumption frequency of fish was registered on a 13-point scale that ranged from 'never' (1) to 'seven times per week' (13). The question was asked for fish in general as well as for farmed and wild fish. For convenience-matters, the scale was rescaled to average weekly consumption frequency, thus ranging from zero to seven. An indirect measurement for consumer awareness of fish origin was derived from the relationship between the three reported consumption frequencies as indicated in formula (1), which results in a percentage. The closer the percentage fits to 100 , the higher the awareness of fish origin.

\footnotetext{
Awareness of fish origin

$(($ Self reported farmed fish consumption frequency + Self reported wild fish consumption frequency $) \times 100)$ Self reported total fish consumption frequency
}

Second, consumers' general attitude towards eating fish was measured, applying a derivate of Sparks and Guthrie (1998). Attitude was measured on seven point semantic differentials for four bipolar items, with the negative item at the scale's left hand side. The 
Table 1 Socio-demographic characteristics of samples of the different countries $(n=1,319)$

\begin{tabular}{|c|c|c|c|c|}
\hline$n$ & $\begin{array}{l}\text { Belgium } \\
440\end{array}$ & $\begin{array}{l}\text { Norway } \\
442\end{array}$ & $\begin{array}{l}\text { Spain } \\
437\end{array}$ & $\begin{array}{l}\text { Total } \\
1,319\end{array}$ \\
\hline \multicolumn{5}{|l|}{ Gender $(\%)$} \\
\hline Females & 64.8 & 63.8 & 65.4 & 64.7 \\
\hline \multicolumn{5}{|l|}{ Age distribution $(\%)$} \\
\hline 20-29 years old & 24.8 & 24.2 & 24.7 & 24.6 \\
\hline 30-39 years old & 25.2 & 25.1 & 24.5 & 24.9 \\
\hline 40-49 years old & 24.3 & 25.3 & 25.2 & 24.9 \\
\hline $50-60$ years old & 25.7 & 25.3 & 25.6 & 25.5 \\
\hline \multicolumn{5}{|l|}{ Education level $(\%)$} \\
\hline Secondary and lower & 47.9 & 30.8 & 44.2 & 40.9 \\
\hline Higher & 52.1 & 69.2 & 55.8 & 59.1 \\
\hline \multicolumn{5}{|c|}{ Presence of children in the household (\%) } \\
\hline Yes & 60.4 & 54.9 & 55.4 & 56.9 \\
\hline No & 39.6 & 45.1 & 44.6 & 43.1 \\
\hline \multicolumn{5}{|l|}{ Household size $(\%)$} \\
\hline 1 person & 18.0 & 23.8 & 9.6 & 17.1 \\
\hline 2 persons & 31.6 & 36.7 & 32.0 & 33.4 \\
\hline 3 persons & 23.0 & 18.8 & 27.5 & 23.1 \\
\hline$\geq 4$ persons & 27.5 & 20.8 & 30.9 & 26.4 \\
\hline \multicolumn{5}{|l|}{ Regional distribution (\%) } \\
\hline Rural area or village & 45.9 & 40.4 & 19.0 & 35.1 \\
\hline Small or middle sized town & 31.1 & 31.4 & 43.8 & 35.4 \\
\hline Large town & 23.0 & 28.2 & 37.2 & 29.5 \\
\hline
\end{tabular}

bipolar items used in the contstruct were bad-good, unsatisfied-satisfied, unpleasantpleasant and negative-positive.

Third, consumers were probed for their involvement in health. Involvement in health was measured using the six statements: health means a lot to me, I care a lot about health, I do whatever I can to stay healthy, healthy food is important for me, I am very involved in health issues and it is important for me to have variation in my diet. Statements were rated on a seven point Likert agreement scale with extreme values 'totally disagree' (1) and 'totally agree' (7).

Fourth, personal data in terms of socio-demographics were questioned.

Statistical analyses

Questionnaires were quality-checked and edited by the field research agency (IPSOS) in order to ensure accuracy and precision of the response prior to coding and transcription of the data. Statistical analyses were performed using the statistical software SPSS version 15.0. Principal component analysis (PCA) with varimax rotation and Cronbach's alpha reliability checks are performed to confirm unidimensionality of the items relating to general attitude and health involvement and to allow further analyses with the averaged construct scores. Both constructs had and alpha value of 0.92 , indicating ample internal reliability consistency, thus allowing the computation of a single construct score for each 
construct. Statistical analyses include descriptive statistics (reporting of means and standard deviations); bivariate correlation analysis; One-Way ANOVA with Bonferroni posthoc testing for analysing between-country differences of mean scores on relevant variables; and cross-tabulations with Chi-square statistics for testing associations between categorical variables.

Considering the differences between countries, subjects from each country were then separated into groups of low and high involvement in health within each country, using the estimated medians of the construct. When reported values for health involvement were below the median, participants were allocated to the low health involvement group. When the reported values where above the median, the participant was allocated to the high involvement group. Group socio-demographics were described using cross-tabulation and differences were tested using Pearson chi-square test. When health involvement group means were compared, differences were tested in ANOVA models (Hair et al. 2006).

Finally, the effect of the health involvement on fish consumption was tested in a separate general linear model (GLM) for each country. In these models the categorical variable related to health involvement was the independent factor and fish consumption the dependent one. Differences and associations were considered statistically significant if the $P$ value was lower than 0.05 .

\section{Results}

Data reduction

Using PCA, the items that represented health involvement and attitudes towards fish consumption where grouped into two factor variables (Table 2).

Table 2 Principle component analysis (PCA) results for the factor variables health involvement and attitudes towards fish consumption, to confirm data reduction

\begin{tabular}{|c|c|c|c|c|}
\hline Factor* & Variable & $\begin{array}{l}\text { Factor } \\
\text { loading }\end{array}$ & $\begin{array}{l}\text { Cronbach } \\
\alpha\end{array}$ & $\begin{array}{l}\text { Explained } \\
\text { variance }\end{array}$ \\
\hline \multirow[t]{6}{*}{ Health involvement } & Health means a lot to me & 0.89 & \multirow[t]{6}{*}{0.92} & \multirow[t]{6}{*}{$71.7 \%$} \\
\hline & I care a lot about health & 0.88 & & \\
\hline & I do whatever I can to stay healthy & 0.87 & & \\
\hline & Healthy food is important for me & 0.86 & & \\
\hline & I am very involved in health issues & 0.84 & & \\
\hline & $\begin{array}{l}\text { It is important for me to have variation in } \\
\text { my diet }\end{array}$ & 0.74 & & \\
\hline \multirow[t]{4}{*}{$\begin{array}{l}\text { Attitudes towards fish } \\
\text { consumption }\end{array}$} & $\begin{array}{l}\text { When I eat fish, I am feeling unpleasant- } \\
\text { pleasant }\end{array}$ & 0.93 & \multirow[t]{4}{*}{0.92} & \multirow[t]{4}{*}{$81.2 \%$} \\
\hline & $\begin{array}{l}\text { When I eat fish, I am feeling unsatisfied- } \\
\text { satisfied }\end{array}$ & 0.92 & & \\
\hline & When I eat fish, I am feeling bad-good & 0.89 & & \\
\hline & $\begin{array}{l}\text { When I eat fish, I am feeling negative- } \\
\text { positive }\end{array}$ & 0.87 & & \\
\hline
\end{tabular}

* Varimax rotated 
Cross-country differences in fish consumption

Significant differences in fish consumption frequency and awareness of the origin of fish were reported by consumers across the three countries (Table 3). Total fish consumption was the highest in Spain, and did not differ between Norwegians and Belgians 16.1\% of the Belgians, $31.2 \%$ of the Norwegians and $58.4 \%$ of the Spaniards met the food recommendations of 2 or more servings of fish per week. Wild fish consumption was the lowest in Belgium, followed by Norway and the highest in Spain. Consumers in Spain were the most aware of the type of fish they consume, followed by the Norwegian and Belgian consumers. However, this difference was only significant between the Spaniards and the Belgians.

Cross-country differences in health involvement and attitudes towards fish consumption

Involvement in health was significantly higher in Belgium and Spain than in Norway (Table 4). Attitudes towards fish consumption were generally positive, resulting to a mean above the scales mid-point. In particular, Spanish consumers held more positive attitudes towards fish consumption than the Belgians.

\section{Relationships with fish consumption}

The correlations between health involvement, attitudes towards fish consumption and fish consumption are shown in Table 5. The data suggested that the relationships between the variables are comparable between the countries. In Belgium, Norway and Spain, involvement in health and attitudes towards fish consumption were significantly and positively correlated with all three fish consumption variables. Despite these significant results, no significant association between health involvement and attitudes with the awareness of the origin of the fish was found.

\section{Differences between health involvement groups}

Consumers from each country were separated into groups of low and high involvement in health, using the median split procedure within each country. The medians for Belgium,

Table 3 Mean (standard deviation) differences in total fish consumption (Consumption is measured in consumption occasions per week), farmed fish consumption (Consumption is measured in consumption occasions per week), wild fish consumption (Consumption is measured in consumption occasions per week) and consumers' awareness of the origin of consumed fish between countries

\begin{tabular}{lcrrr}
\hline & \multicolumn{2}{l}{ Country } & & \\
\cline { 2 - 5 } & Belgium & Norway & Spain & $F_{2,1318}$ \\
\hline Total fish consumption per week & $0.89(0.76)^{\mathrm{c}}$ & $1.24(1.09)^{\mathrm{b}}$ & $2.10(1.45)^{\mathrm{a}}$ & $131.744^{* *}$ \\
Farmed fish consumption per week & $0.39(0.60)^{\mathrm{b}}$ & $0.47(0.68)^{\mathrm{b}}$ & $0.94(1.13)^{\mathrm{a}}$ & $56.075^{* *}$ \\
Wild fish consumption per week & $0.24(0.49)^{\mathrm{c}}$ & $0.42(0.68)^{\mathrm{b}}$ & $0.79(1.13)^{\mathrm{a}}$ & $52.754^{* *}$ \\
$\%$ Awareness of fish origin & $69.9(78.9)^{\mathrm{b}}$ & $78.6(59.8)^{\mathrm{a}, \mathrm{b}}$ & $85.2(68.38)^{\mathrm{a}}$ & $5.169^{*}$ \\
\hline
\end{tabular}

${ }^{a-c}$ Significantly different means using Bonferoni post hoc tests, with country as a factor variable

$* P<0.01$ based on Analysis of variance

** $P<0.001$ based on Analysis of variance 
Table 4 Differences in involvement in health and attitudes towards fish consumption between countries (mean scores and standard deviation)

\begin{tabular}{lllll}
\hline & Country & & \multirow{2}{*}{$\mathrm{F}_{2,1318}$} \\
\cline { 2 - 4 } & Belgium & Norway & Spain & \\
\hline Involvement with health & $5.44(1.14)^{\mathrm{a}}$ & $4.74(1.26)^{\mathrm{b}}$ & $5.57(1.10)^{\mathrm{a}}$ & \multirow{2}{*}{$63.984^{*}$} \\
Attitudes towards fish consumption & $5.28(1.48)^{\mathrm{b}}$ & $5.50(1.59)^{\mathrm{a}, \mathrm{b}}$ & $5.66(1.47)^{\mathrm{a}}$ & $7.254^{* *}$ \\
\hline
\end{tabular}

$\overline{a-c}$ Significantly different means using Bonferoni post hoc tests, with country as a factor variable

$* P<0.001$ based on Analysis of variance

** $P<0.01$ based on Analysis of variance

Norway and Spain were respectively 5.63, 4.79 and 5.70. Differences regarding sociodemographic characteristics were found between the two health involvement groups in all countries (Table 6).

In all three countries, high health involved consumers were associated more with being female and older, as shown by significant chi-square tests in Table 6. In Belgium and Norway, the higher health involved group was also composed of a higher share of households with children.

Consumers' attitudes towards fish consumption (Fig. 1) differed significantly between health involvement groups. In each of the countries, consumers that were involved in health had more positive attitudes towards fish consumption (Belgium: $F_{1,439}=31.494$; $P<0,001$, Norway: $F_{1,441}=17.742 ; P<0.001$ and Spain: $\left.F_{1,439}=31.494 ; P<0.001\right)$.

In Belgium, total fish consumption $\left(F_{1,439}=19.95 ; P<0.001\right)$, farmed fish consumption $\left(F_{1,439}=6.13 ; P=0.014\right)$ and wild fish consumption $\left(F_{1,439}=10.58\right.$; $P=0.001)$ were significantly higher for the group with a higher involvement in health (Fig. 2).

In Norway, total fish consumption $\left(F_{1,441}=31.41 ; P<0.001\right)$, farmed fish consumption $\left(F_{1,441}=9.38 ; P=0.002\right)$ and wild fish consumption $\left(F_{1,441}=14.19 ; P<0.001\right)$ were significantly higher for the group with a higher involvement in health (Fig. 3).

Finally in Spain we found a higher total fish consumption $\left(F_{1,436}=20.20 ; P<0.001\right)$ and farmed fish consumption $\left(F_{1,436}=5.71 ; P=0.017\right)$ for the group with a higher involvement in health (Fig. 4). Even though wild fish consumption followed a similar trend, it was not significantly different between the groups of high and low involvement in health $\left(F_{1,436}=2.51 ; P=0.114\right)$.

A comparison of consumers' awareness of the origin of the fish they consume is presented in Fig. 5. The data from Belgium and Norway suggested a tendency that consumers' health involvement was associated with awareness of the origin of the fish they consume. However, none of these differences were significant and an opposite trend was observed for Spain (Belgium: $F_{1,415}=2.42 ; P=0.120$; Norway: $F_{1,431}=1.68$; $P=0.195$; Spain: $\left.F_{1,432}=0.33 ; P=0.568\right)$.

\section{Discussion and conclusion}

The present study showed differences in reported total, farmed and wild fish consumption frequency in people responsible for food purchasing in the age range 20-60 years from Belgium, Norway and Spain. Spanish consumers consumed fish most frequently, Belgian 


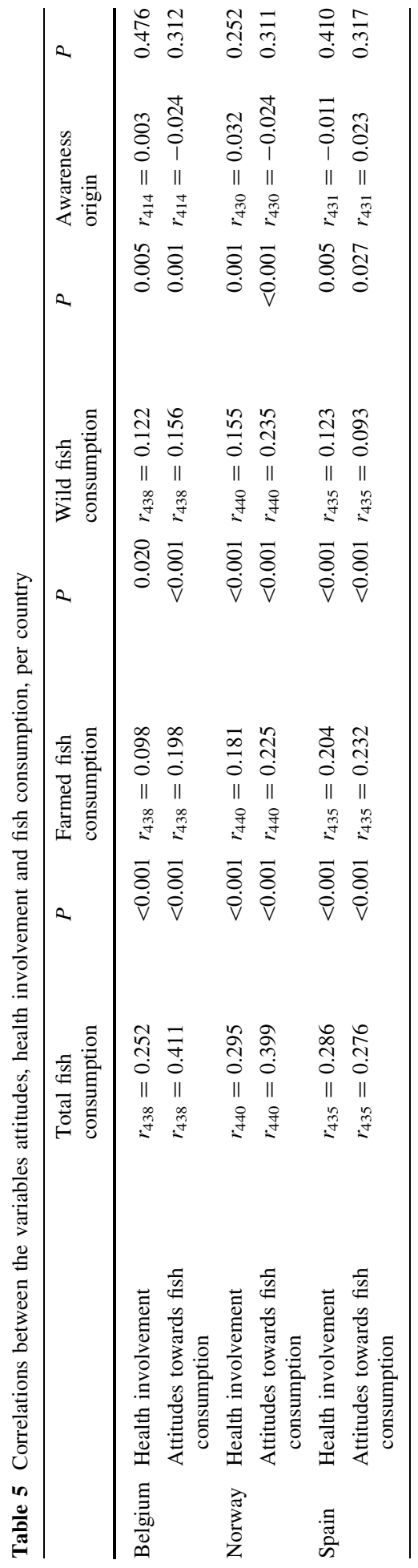


Table 6 Socio-demographic characteristics (\% of the respondents) between high and low health involvement groups within each country

\begin{tabular}{|c|c|c|c|c|c|}
\hline \multirow[t]{2}{*}{ Country } & \multirow{2}{*}{ Characteristic } & \multicolumn{2}{|c|}{ Health involvement } & \multirow[t]{2}{*}{ Total } & \multirow[t]{2}{*}{$P$ value $^{\mathrm{a}}$} \\
\hline & & Low & High & & \\
\hline \multirow[t]{14}{*}{ Belgium } & $n$ & 218 & 222 & 440 & \\
\hline & Gender & & & & \\
\hline & Females & 57.3 & 72.1 & 64.8 & 0.001 \\
\hline & Age & & & & \\
\hline & $20-29$ & 31.3 & 18.5 & 24.8 & 0.001 \\
\hline & $30-39$ & 24.3 & 26.1 & 25.2 & \\
\hline & $40-49$ & 26.1 & 22.5 & 24.3 & \\
\hline & $50-60$ & 18.3 & 32.9 & 25.7 & \\
\hline & Education & & & & \\
\hline & Secondary and lower & 46.8 & 49.1 & 47.9 & 0.628 \\
\hline & Children & & & & \\
\hline & In household & 54.2 & 66.3 & 60.4 & 0.002 \\
\hline & Not in household & 10.7 & 15.2 & 13.0 & \\
\hline & No children & 35.1 & 18.5 & 26.6 & \\
\hline \multicolumn{6}{|l|}{ Norway } \\
\hline & $n$ & 221 & 221 & 442 & \\
\hline & Gender & & & & \\
\hline & Females & 54.8 & 72.9 & 63.8 & $<0.001$ \\
\hline & Age & & & & \\
\hline & $20-29$ & 28.5 & 19.9 & 24.3 & 0.031 \\
\hline & $30-39$ & 24.9 & 25.3 & 25.1 & \\
\hline & $40-49$ & 26.7 & 24.0 & 25.3 & \\
\hline & $50-60$ & 19.9 & 30.8 & 25.3 & \\
\hline & Education & & & & \\
\hline & Secondary and lower & 34.4 & 27.1 & 30.8 & 0.099 \\
\hline & Children & & & & \\
\hline & In household & 49.1 & 60.2 & 54.9 & 0.090 \\
\hline & Not in household & 18.0 & 16.5 & 17.2 & \\
\hline & No children & 32.9 & 23.3 & 27.9 & \\
\hline \multicolumn{6}{|l|}{ Spain } \\
\hline & $n$ & 219 & 218 & 437 & \\
\hline & Gender & & & & \\
\hline & Females & 59.4 & 71.6 & 65.4 & 0.007 \\
\hline & Age & & & & \\
\hline & $20-29$ & 24.2 & 25.2 & 24.7 & 0.096 \\
\hline & $30-39$ & 28.8 & 20.2 & 24.5 & \\
\hline & $40-49$ & 25.6 & 24.8 & 25.2 & \\
\hline & $50-60$ & 21.4 & 29.8 & 25.6 & \\
\hline & Education & & & & \\
\hline & Secondary and lower & 42.9 & 45.4 & 44.2 & 0.600 \\
\hline & Children & & & & \\
\hline & In household & 53.8 & 57.1 & 55.4 & 0.318 \\
\hline & Not in household & 7.1 & 10.1 & 8.7 & \\
\hline & No children & 39.1 & 32.8 & 35.9 & \\
\hline
\end{tabular}

${ }^{\text {a }}$ Pearson $\chi^{2}$ test 


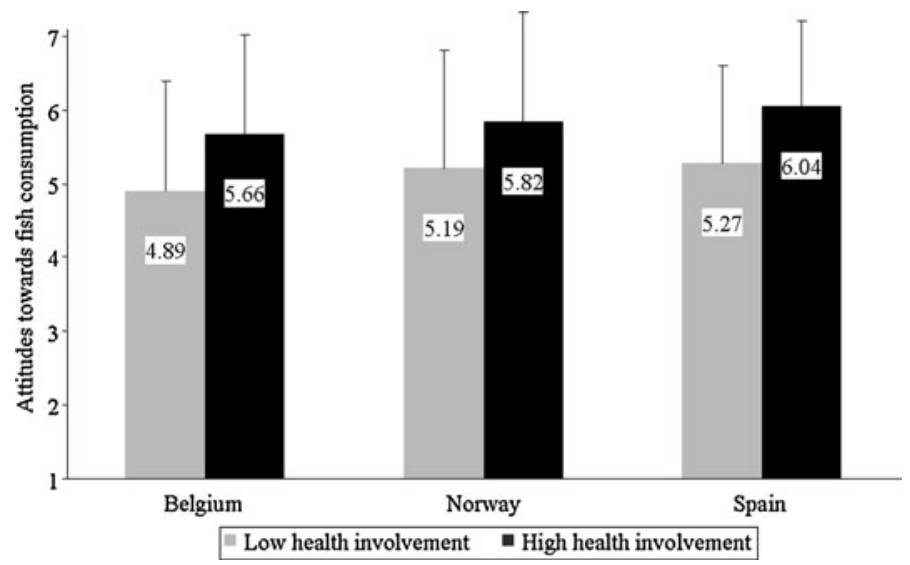

Fig. 1 Mean (standard deviation) attitude towards fish consumption, rated on a 7 point scale from negative attitude (1) to positive attitude (7)

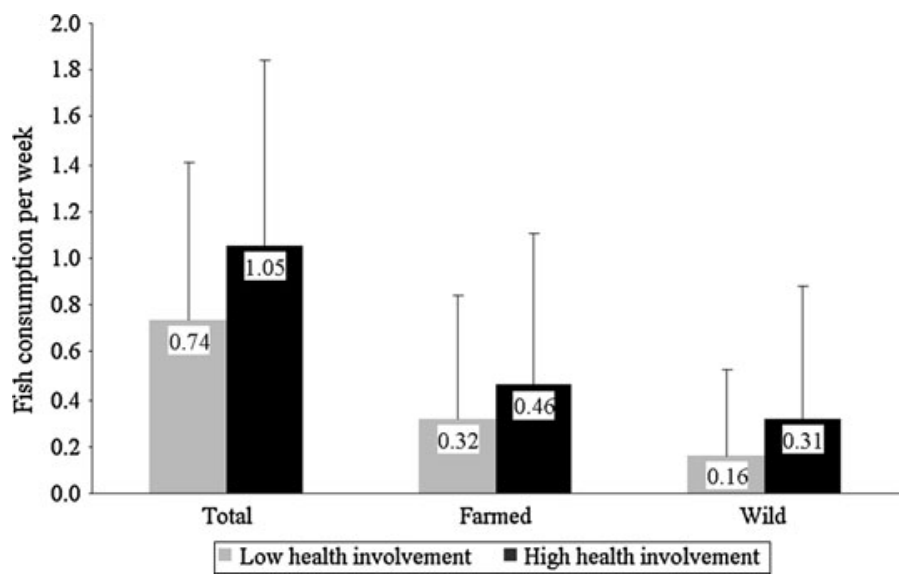

Fig. 2 Mean (standard deviation) total, farmed and wild fish consumption (meals per week) by health involvement group in Belgium

consumers least frequently. Accordingly, health involvement and attitudes towards fish consumption were the lowest in Belgium, higher in Norway and the highest in Spain. Both, high health involvement and more positive attitudes towards fish consumption were suggested to positively associate with total fish consumption. In line with the lower fish consumption rates, we found Belgians also to be least aware of the fish's origin. The level of health involvement did not associate with the level of awareness within countries. In general consumers appeared to be rather poorly aware of the fish they consume being farmed or wild.

In agreement with Olsen (2003) the present study presented that involvement in health is an issue that varies with age. It was indicated that single, young males were the least involved in health and the consumption of healthy food, opposing the less young, non single females. Additionally, it was shown that attitudes towards the consumption of fish were significantly associated with fish consumption. Health involvement was found by 


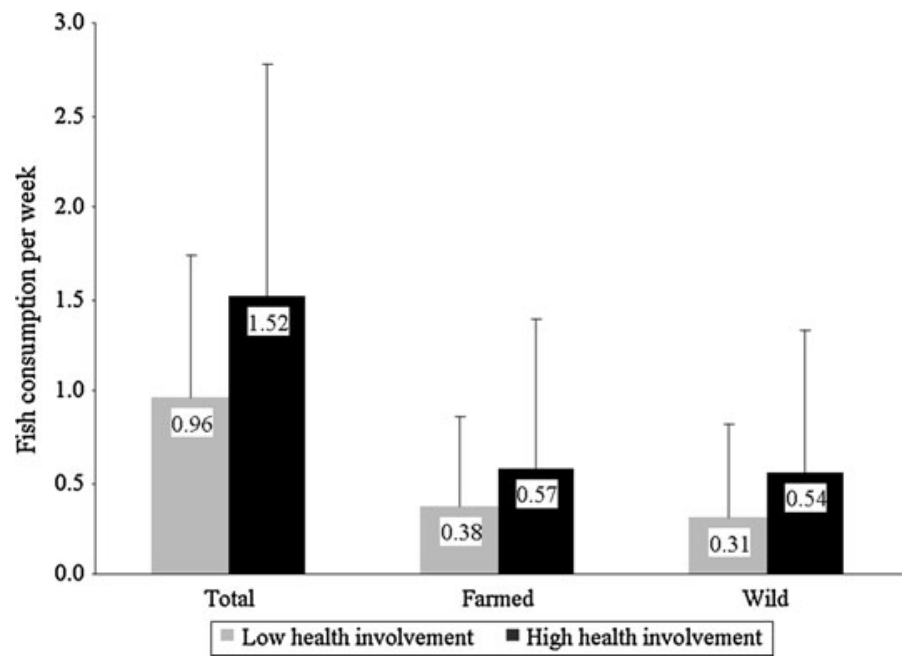

Fig. 3 Mean (standard deviation) total, farmed and wild fish consumption (meals per week) by health involvement group in Norway

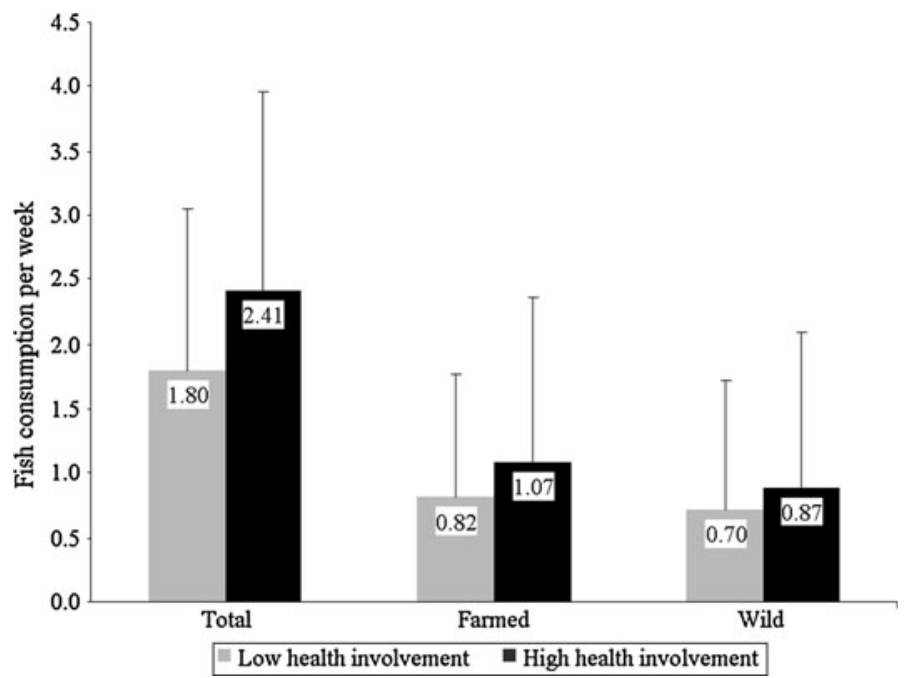

Fig. 4 Mean (standard deviation) total, farmed and wild fish consumption (meals per week) by health involvement group in Spain

Olsen to be a strong predictor of the attitudes towards fish consumption, which in the present study was expanded as being present in Belgium, Norway and Spain. Pieniak et al. (2008) showed that involvement in health affects interest in healthy eating, which influences total fish consumption. This was clearly exemplified before, when younger subjects where found to be weakly influenced by health related attributes of food (Roininen et al. 1999 ) or by environmental changes that could increase convenience and access to healthier choices (Wiegersma et al. 2000). 


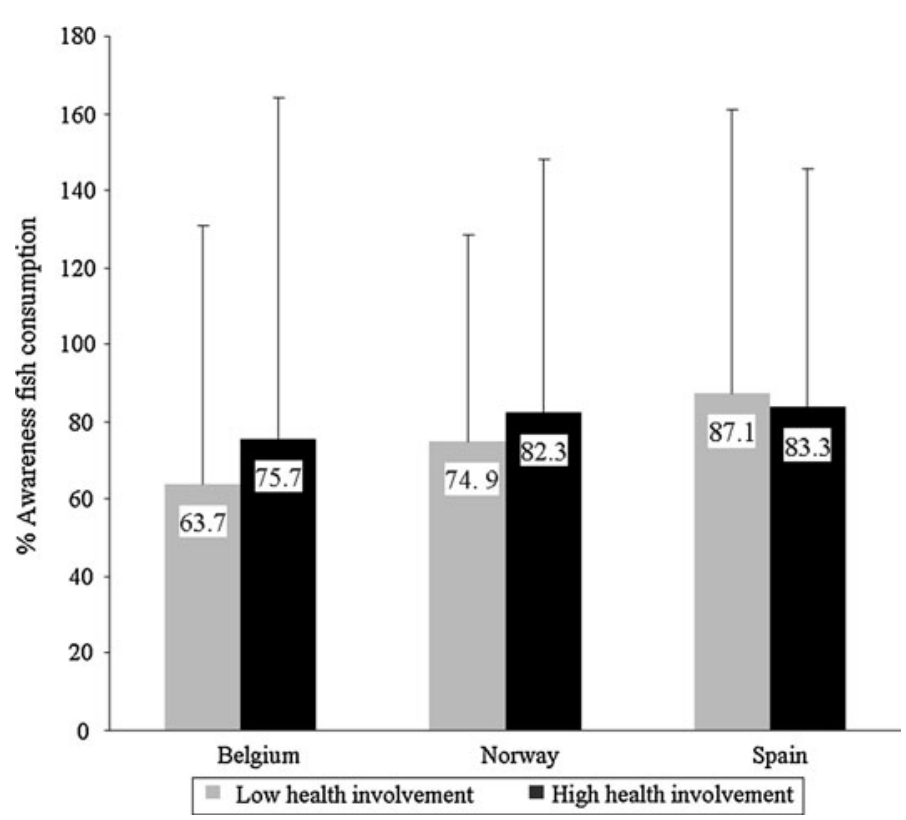

Fig. 5 Consumers' awareness of the origin of the fish they consume in Belgium, Norway and Spain

Combining the present findings with the previous two by Olsen (2003) and Pieniak et al. (2008), we conclude that health involvement is associated with age. Furthermore, there is a direct relationship of health involvement with fish consumption. Additionally, attitudes towards fish consumption were positively associated with fish consumption and as it has been previously discussed, that could be amplified by a high involvement in health. The present study expanded these findings by showing that the same effects are present in Belgium, Norway and Spain. Additionally, this study explored fish consumption in depth and presented that health involvement and attitudes towards fish consumption are associated with the consumption of both farmed and wild fish.

Interesting tendencies towards the explanation of discrepancies between the effects of socially desirable product characteristics on actual eating behaviour were presented, in a correlational manner. Experimental validation of these results would provide stronger evidence on the potency of the impact of the sensory and health related image of farmed fish on fish consumption.

The main outcome of this study is that involvement in health issues and attitudes towards fish consumption are associated with fish consumption in a positive manner. This influence is present for farmed and wild fish consumption. Belgium, Norway and Spain are three countries which are located in the central, the northern and southern part of Europe and represent low, medium and high fish consumption behaviour respectively. However, health involvement and attitudes are associated with fish consumption equally across them. Self reported consumption frequency was also found to be associated with the awareness of the origin of the consumed fish. In summary, this study demonstrated that different types of consumers in Belgium, Norway and Spain may chose for farmed and wild fish based on their involvement in health issues and their attitudes towards fish consumption. 
Acknowledgments Consensus and the Commission of European Communities (6th Framework Programme thematic priority "Food Quality and Safety" contract FOOD-CT-2005-513998) are acknowledged for the financial support of the present study.

Open Access This article is distributed under the terms of the Creative Commons Attribution Noncommercial License which permits any noncommercial use, distribution, and reproduction in any medium, provided the original author(s) and source are credited.

\section{References}

Bem DJ (1972) Self-perception theory. In: Advances in experimental social psychology, vol 6. Academic press, New York, pp 1-62

Brislin RW (1970) Back-translation for cross-cultural research. Journal of Cross-cultural Psychology $1: 185-216$

Bruns $\varnothing$ K (2003) Consumer research on fish in Europe. In: Luten JB, Oehlenschlaeger J, Olafsdottir G (eds) Quality of fish from catch to consumer: labelling, monitoring and traceability. Wageningen Academic Publishers, Wageningen, pp 335-344

Hair J, Black B, Babin B, Anderson R, Tatham R (2006) Multivariate data analysis, 6th edn. Prentice-Hall, Upper Saddle River

Honkanen P, Olsen SO, Verplanken B (2005) Intention to consume seafood-the importance of habit. Appetite 45(2):161-168

Kole A (2003) Consumer opinions towards farmed fish, accounting for relevance and individual knowledge. In: Luten JB, Oehlenschlaeger J, Ólafsdóttir AS (eds) Quality of fish from catch to consumer. Wageningen academic publisher, Wageningen, pp 393-400

Kole APW, Altintzoglou T, Schelvis-Smit RAAM et al (2009) The effects of different types of product information on the consumer product evaluation for fresh cod in real life settings. Food Qual Prefer 20(3):187-194

Köster EP (2009) Diversity in the determinants of food choice: a psychological perspective. Food Qual Prefer 20(2):70-82

Köster EP, Beckers A, Houben JB (1987) The influence of health information on the acceptance of a snack in a canteen test. In: Martens M, Dalen GA, Russwurm H (eds) Flavour science and technology. Wiley, Chichester, New York, pp 391-398

Kozup JC, Creyer EH, Burton S (2003) Making healthful food choices: the influence of health claims and nutrition information on consumers' evaluations of packaged food products and restaurant menu items. Journal of Marketing 67(2):19-34

Luten J, Kole A, Schelvis R et al (2002) Evaluation of wild cod versus wild caught, farmed raised cod from Norway by Dutch consumers. Økonomisk Fiskeriforskning 2002(12):44-60

Malhotra NK, Peterson M (2006) Basic marketing research: a decision-making approach. Pearson Education, Prentice Hall, Upper Saddle River

Maneesriwongul W, Dixon JK (2004) Instrument translation process: a methods review. J Adv Nurs 48: $175-186$

Mozaffarian D, Rimm EB (2006) Fish intake, contaminants, and human health-evaluating the risks and the benefits. Jama-Journal of the American Medical Association 296(15):1885-1899

Olsen SO (2001) Consumer involvement in seafood as family meals in Norway: an application of the expectancy-value approach. Appetite 36(2):173-186

Olsen SO (2003) Understanding the relationship between age and seafood consumption: the mediating role of attitude, health involvement and convenience. Food Qual Prefer 14(3):199-209

Olsen SO, Scholderer J, Brunsø K et al (2007) Exploring the relationship between convenience and fish consumption: a cross-cultural study. Appetite 49(1):84-91

Pieniak Z, Verbeke W, Scholderer J et al (2008) Impact of consumers' health beliefs, involvement and risk perception on fish consumption: a study in five European countries. British Food Journal 110(9): 898-915

Roininen K, Lahteenmaki L, Tuorila H (1999) Quantification of consumer attitudes to health and hedonic characteristics of foods. Appetite 33(1):71-88

Rortveit AW, Olsen SO (2007) The role of consideration set size in explaining fish consumption. Appetite 49(1):214-222

Scientific Advisory Committee on Nutrition, Committee on toxicity of chemicals in food (2004) Advice on fish consumption: benefits and risks. TSO, London 
Sidhu KS (2003) Health benefits and potential risks related to consumption of fish or fish oil. Regul Toxicol Pharmacol 38(3):336-344

Sparks P, Guthrie CA (1998) Self-identity and the theory of planned behavior: a useful addition or an unhelpful artifice? J Appl Soc Psychol 28:1393-1410

Verbeke W, Sioen I, Pieniak Z et al (2005) Consumer perception versus scientific evidence about health benefits and safety risks from fish consumption. Public Health Nutrition 8(4):422-429

Verbeke W, Sioen I, Brunsø K, De Henauw S, Van Camp J (2007a) Consumer perception versus scientific evidence of farmed and wild fish: exploratory insights from Belgium. Aquacult Int 15(2):121-136

Verbeke W, Vermeir I, Brunsø K (2007b) Consumer evaluation of fish quality as basis for fish market segmentation. Food Qual Prefer 18(4):651-661

Weijzen PLG, de Graaf C, Dijksterhuis GB (2008) Discrepancy between snack choice intentions and behavior. Journal of Nutrition Education and Behavior 40(5):311-316

Welch A, Lund E, Amiano P et al (2002) Variability of fish consumption within the 10 European countries participating in the European Investigation into Cancer and Nutrition (EPIC) study. Public Health Nutrition 5:1273-1285

Wiegersma PA, Hofman A, Zielhuis GA (2000) Prevention of unhealthy behaviour by youth health care in The Netherlands. J Public Health Med 22(3):386-392 